\title{
A Frontline Driver at Crossroads
}

\author{
Hune Cho, $\mathrm{PhD}$
}

Department of Medical Informatics, School of Medicine, Kyungpook National University, Daegu, Korea

In Korea driving is no piece of cake as someone puts it: "Everyone is driving like crazy, with no one getting anywhere." Suppose you are driven into the frontline at intersection, waiting for the signal ready to drive on. Even during such a short while your mind is blown away or you may answer the cellular phone, letting you forget what you are waiting for. When signal turns green, a little chaos breaks out. Immediately one or two horn goes off, and the drivers behind you start ducking out left or right to go ahead of you. The single lane quickly turns into spaghetti and the degree of chaos grows exponentially. It could be much worse if a collision takes place. The whole disaster wouldn't happen if you responded the signal instantly. Without your negligence you life would stay on the fast lane, but in vain. The point is that a moment at the forefront is 100 times more precious than a moment in the rear. So be attentive when are running ahead of others.

We were once frontliners for a quite while when the Korean Society of Medical Informatics (KOSMI) was founded in 1987. Despite a small number of KOSMI members, we were one of a mind and we accomplished many wonderful things such as MEDINFO '98. A large number of hospital information systems were successfully implemented due to continuing efforts of the KOSMI with the support of sophisticated information technology (IT) advancements. Before the turn of the 21 century, as a result, nearly all hospitals in Korea operated and running information systems so that electronic insurance claims and reimbursements using EDI global standard were highly promoted. As soon as Y2K crisis was overcome, Picture Archiving and Communication Systems (PACS) were rapidly facilitated in hospitals; thus Korea

This is an Open Access article distributed under the terms of the Creative Commons Attribution Non-Commercial License (http://creativecommons.org/licenses/bync/3.0/) which permits unrestricted non-commercial use, distribution, and reproduction in any medium, provided the original work is properly cited.

(c) 2011 The Korean Society of Medical Informatics has been recognized as the most medical IT-strong nation worldwide. As of now, a few leading university hospitals start implementing Electronic Medical Record (EMR), for which government funded research related to Electronic Health Record (EHR) is under consideration. We are proud to say that behind every great achievements in medical IT, KOSMI was there.

Suddenly from some time ago and on, Korea lost her touch in IT. Though IT governance and social networking services are spread wider and deeper, the software frontier spirits are vanishing. Retrospective study has indicated that collective intelligence is not always right for the majority of those who are strongly biased in the struggle of conflicts of interests. Finally, the Ministry of Information and Communication has been decomposed. Is it all "none-of-my-business" to KOSMI? I am afraid that is not the case. Where have all the good old spirits of medical informatics gone?

The first decade of the 21 century appeared rather quiet compared to the second period. Since last year we have seen many striking changes such as TGIF (short for twitter, google, iPhone, facebook). It seems to me a whole new IT paradigm tides in. The unexpected south-east wind baffles many smart brains all over the world. The Korea's IT-strong legend is breaking apart as the whole world rapidly moves towards a wireless monolithic empire. KOSMI, along with Korea, believed to some extent that the prosperity we now have may continue for a long time but it turns out to be a daydream. Come to think of the past decades IT people in Korea were frontliners but their minds were blown away with something else. When TGIF comes up in the marketplace, competition is almost out of the question. Though major conglomerates in Korea are still breathing in the market, no one would dare to say that IT-Korea will rock the world again. I am pessimistic until information scientists in Korea redefine IT because IT-strong Korea is like a castle in the air. For example, the semiconductor is mistakenly classified as IT, although there is no software component in it. Data or 
information can be stored on a hardware platform, but IT must consist of content and software, not necessarily including hardware.

The new agenda for the national growth engine includes medical industry to be a leading business entity for the 21 century. With tons of smart IT engineers in medical and healthcare fields, nothing would be impossible. I would say, however, "In hospital every IT engineer is developing crazy, with no application working anywhere right." National information infrastructure must upgrade to the level of global standards. No business in medicine can be established without standard network and legal infrastructure. On the other hand, I am optimistic for the future of medical informatics because active human participation is essential in the development of medical software that has been disregarded in many IT-centric implementations. Softwares of medical informatics must be developed patient-centric and contents must be validated by accredited healthcare professionals. Medicine is known to be more than 2,500 years old profession. Very recently and suddenly IT is exploding and expanding its magnitude and territory at the speed of light, therefore I have a dream that medicine and IT will be synergistically integrated to make both KOSMI and Korea proud.

"My heart leaps up when I behold, A rainbow is in the sky."

Medical informatics is like a rainbow to me. So was it when I started my degree, so is it now I am a KOSMI member, and so be it when I grow for retire. I have a vision with the faith that one day healthcare providers and IT engineers, sitting around the table being able to speak fluently to exchange and share profound multidisciplinary knowledge of the other's profession. The KOSMI tradition must continue and the good spirit must be kept. There is an old saying that "A good beginning is half done." Since we have begun the good beginning, we have high hopes for KOSMI to be a rolling stone for many decades to come in the medical and healthcare informatics societies. 